\title{
Foreword
}

John Funder

Published online: 12 April 2011

(C) Springer Science+Business Media, LLC 2011

In the September 2008 issue of the Journal of Clinical Endocrinology and Metabolism, the Endocrine Society published "Case detection, diagnosis and treatment of patients with primary aldosteronism: an Endocrine Society clinical guideline". Subsequently these guidelines were published in the European Journal of Endocrinology, and similar but not identical guidelines in Japan.

The Endocrine Society guidelines were the product of 2 years work by a small task force, which marshalled evidence over that time, and met both face to face and by teleconference. Consensus was reached-often by majority rather than unanimous agreement — and the draft guidelines were sent out on the website for much wider consultation and input. They were reviewed and refined in response to this consultation, peer-reviewed by normal journal practice, and ultimately published.

For practical (and financial) reasons the taskforce that was charged with developing the guidelines was small, and therefore suboptimally representative. Although it included among its seven members experts from four continents (North America, South America, Europe and Australia), there were no voices from other experts, from areas of major current contributions to the field-elsewhere in Europe, and most particularly in Japan.

This constitutes one of two reasons for the genesis of this issue of the journal. Eleven authors were approached-none of whom served on the Endocrine Society Taskforce-all of whom agreed to contribute, land in the event eight have overcome the multitudinous demands on their time to do so, in

J. Funder $(\bowtie)$

Prince Henry's Institute of Medical Research,

Clayton, Victoria, Australia 3168

e-mail: john.funder@princehenrys.org the pages that follow. As noted, the list includes four additional authors from centres in Europe, and two (of the many contributing centres) from Japan.

The second, and equally relevant, reason for the present publication is that the published guidelines are works-inprogress. This is implicit-for example, in citing the usual 'cut-off' points for the aldosterone to renin ratio, used in screening, without mandating a particular value, or in recommending any one of four confirmatory/exclusion tests, rather than mandating a particular procedure. The guidelines are also explicit in stating that the evidence base for many of the procedures involved in diagnosis and management of the condition is thin or non-existent, and that in many areas informed and expert opinion is in fact the basis upon which decisions are made.

This collection of informed and expert opinion thus represents a contribution to the evolution of how best to manage primary aldosteronism, 3 years down the track. They canvass local usage, report local experience, add to the evidence base-for example, the use of the selective mineralocorticoid receptor antagonist eplerenone, in Europe and Japan, for which there was only anecdotal evidence in 2008. They also, in some instances, and absolutely appropriately, challenge some of the 2008 guidelines, in many senses the raison d'etre of the issue.

As Guest Editor, I owe a debt of thanks to the authors of the articles in the issue, and to the editorial and production staff of Springer - in both cases for the patience and adaptability they showed in the process. Guidelines for clinical practice constantly need refining: this is the first, but surely will not be the last, attempt to do so in the area of primary aldosteronism.

\section{JOHN FUNDER}

Guest Editor 